\title{
A Study on Coupling Faults' Characteristics of Fixed-Axis Gear Crack and Planetary Gear Wear
}

\author{
Xin Wang (iD) \\ School of Mechanical Engineering, Baoji University of Arts and Sciences, Baoji 721016, China \\ Correspondence should be addressed to Xin Wang; 46607190@qq.com
}

Received 15 October 2017; Accepted 1 April 2018; Published 8 May 2018

Academic Editor: Rafał Burdzik

Copyright ( 2018 Xin Wang. This is an open access article distributed under the Creative Commons Attribution License, which permits unrestricted use, distribution, and reproduction in any medium, provided the original work is properly cited.

To identify the fault frequency characteristics of the gear transmission system under coupling fault of fixed-axis gear crack and planetary gear wear, dimensionless dynamical equations of gear transmission system were established. Bifurcations in normal condition and coupling fault condition were contrasted. The affected excitation frequency range was found. Fault frequency characteristics in sensitive interval caused by the coupling fault of fixed-axis gear crack and planetary gear wear were analyzed. Simulation analysis shows that the crack fault in fixed-axis gear brings up peaks in doubling of $1 \sim 10$ for fault frequency, the wear fault in planetary gear increases the amplitude of meshing frequency and its double and triple, and the coupling of both shows two kinds of fault features around the planetary gear meshing frequency.

\section{Introduction}

The wind turbine gearbox is the core component of the wind turbine; its transmission system is a multistage gear transmission system with a two-stage fixed-axis gear and a one-stage planetary gear. The wind turbine gearbox has a high failure rate by the disorder, variable load, and strong impact wind load. The vibration mechanism and fault mechanism of multistage gear transmission system are not clear, so the online monitoring and fault diagnosis of the wind turbine gearbox are not perfect. A lot of fault were not discovered early, resulting in a chain reaction. It makes the whole transmission system downtime, resulting in huge economic loss and bad social impact. Only by studying the vibration mechanism and fault mechanism of the multistage gear transmission system and finding out the complex signal correlation characteristics caused by the fault, can the early fault of the gear be identified by the signal processing method.

There is a large difference between the local fault vibration signal of the planetary gearbox and the fixed-axis gearbox. The dynamic model of the single pair cannot describe the modulation effect of the dynamic signal in the coupling state, and the fault side band of the coupling state cannot be properly extracted. Therefore, it is necessary to delve into the spectral characteristics of the vibration signal of the planetary gearbox (especially in the case of coupling faults), so as to achieve the purpose of fault diagnosis of the planetary gearbox through the fault feature frequency component.

For the study of coupling faults, Li et al. $[1,2]$ used the combined intelligent signal analysis method based on wavelet packet, empirical mode decomposition, Wigner distribution, and AR model to identify five single faults and three coupling faults. Then he proposed a new method [3], using the independent component analysis (ICA - R) as the fault frequency tracking tool to simplify the coupling fault to a single fault. Luo et al. [4] proposed a sparse representation method based on wavelet based compound fault feature extraction, which can separate and extract different transient characteristics of bearings and gears. Xiao-yu et al. [5] differentiated single fault and coupling faults through the correlation dimension and the largest Lyapunov exponent. The research on coupling failure is based on the experimental signal analysis, and its accuracy depends on the large data accuracy. Data of different test rig may contain its unique characteristic and do not have generality for fault diagnosis of other devices. Experimental method cannot distinguish which feature is common feature which is a unique feature and the mechanism of various features. So with research on the nonlinear characteristics 


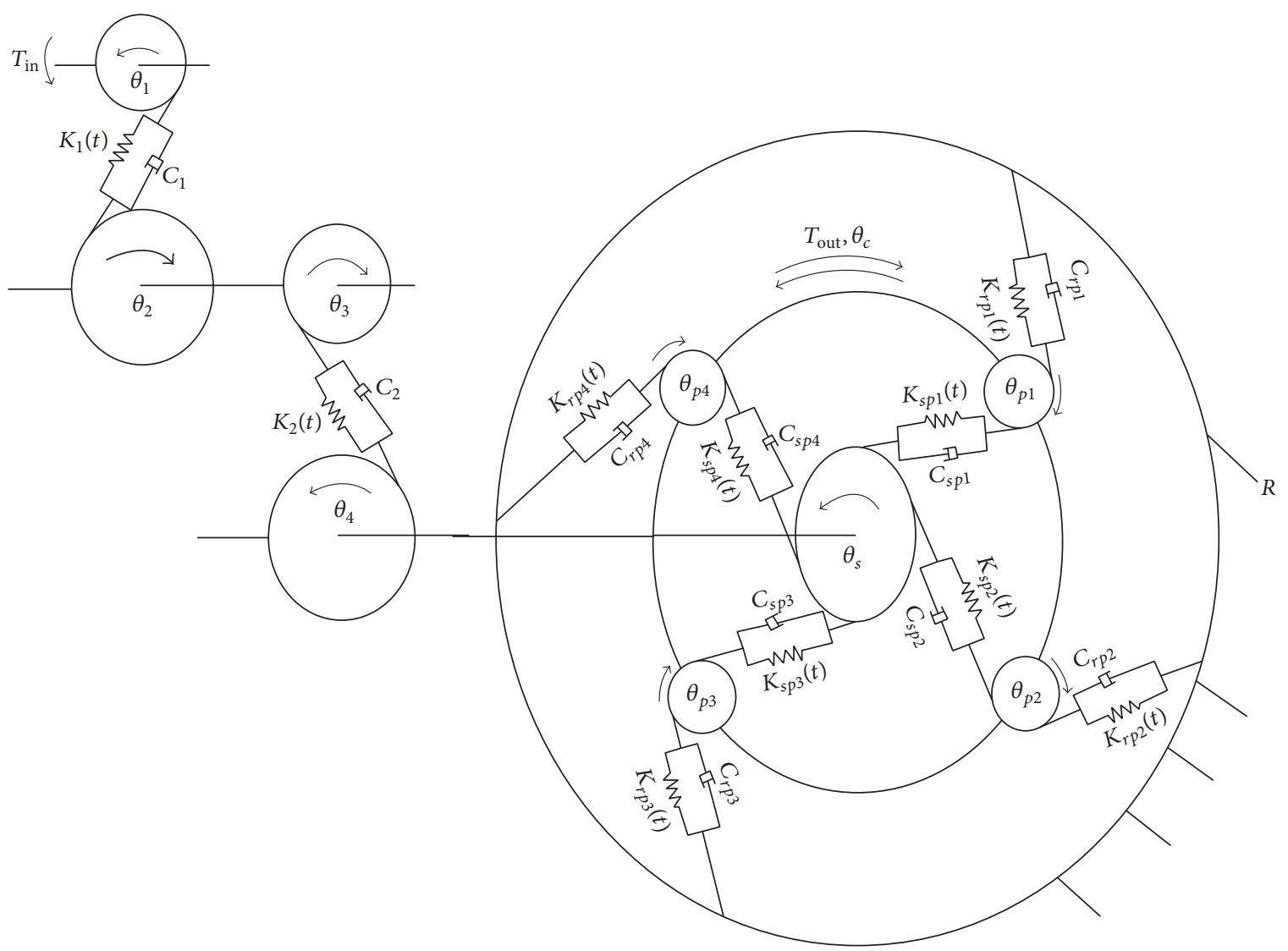

FIGURE 1: Torsional dynamic model of gear transmission system.

and fault mechanism of coupling faults from the angle of bifurcation and chaos characteristics, we can distinguish the changes caused by the coupling effect and find the general characteristics of coupling.

In the article [6], the coupling fault of fixed-axis crack and planetary gear chipping was studied from the nonlinear angle, and the fault frequency characteristics of the coupling fault were analyzed. However, wear fault occurs more frequently and is more difficult to identify than chipping fault. When the system has wear fault, it will affect the clearance between the gears. The clearance is the main cause of the collision movement within the system, which will change the motion state of the system. Therefore, it is of great significance to study the influence of wear fault on the bifurcation characteristics of the system compared with chipping fault. On the basis of article [6], this paper studies the coupling fault of fixed-axis crack and planetary gear wear. The nonlinear dynamic model with the coupling fault of the fixed-axis crack fault and the planetary wear fault is established, and the bifurcation characteristics and coupling fault characteristics of the fixed-axis gear in the system are analyzed by the simulation method in normal state, fixed-axis crack fault state, planetary wear fault state, and coupling fault state. Characteristics and frequency bands of the fault frequency are discussed for different excitation frequencies. According to the numerical simulation results, the fault frequency of the measured signal is identified.

\section{Torsional Dynamic Model of Gear Transmission System}

The system studied in this paper is a test rig of gear transmission system which contains a two-stage fixed-axis gear and a one-stage planetary gear, where spur gears 1 and 2 compose the 1st-stage fixed-axis gear for the input, spur gears 3 and 4 compose the 2nd-stage fixed-axis gear, and the planet carrier is for the output. The torsional dynamic model is established by using the lumped mass method (Figure 1).

When gear system, the drive shaft, bearing, and box bearing stiffness are relatively large, then regardless of their flexibility the gear system turns into pure torsional vibration model. If the gear system input and output shaft stiffness is relatively small, the gear system can be isolated from the prime mover and the load, and a separate vibration model of the gear system can be established. Due to the nonconsideration of the specific vibration form of the transmission shaft, the support stiffness and damping of the transmission shaft, bearing, and box can be expressed as the combined equivalent values. The model does not consider the transverse vibration displacement of gears. Gear parameters are simulated with a spring and a damper.

See Figure 1 , where, $\theta_{s}, \theta_{c}, \theta_{p n}, \theta_{1}, \theta_{2}, \theta_{3}$, and $\theta_{4}$ represent the angular displacement of sun gear, planet carrier, planetary gear $n(n=1,2,3,4)$, and spur gears $1,2,3$, and 4 , respectively. Throughout this paper, the subscripts $s, c, p n, r, 1,2,3$, and 4 
denote sun gear, planet carrier, planetary, ring gear, and spur gears 1, 2, 3, and 4. Quantities $r_{s}, r_{c}, r_{p n}, r_{1}, r_{2}, r_{3}$, and $r_{4}$ are the base circle radius of gears. Quantities $K_{s p n}(t), K_{r p n}(t)$, $K_{1}(t)$, and $K_{2}(t)$ denote the meshing stiffness of sun gear with planetary gear $n$, ring gear with planetary gear $n$, 1st-stage fixed gear, and 2nd-stage fixed gear. Quantities $C_{s p n}, C_{r p n}, C_{1}$, and $C_{2}$ denote the damping of sun gear with planetary gear $n$, ring gear with planetary gear $n$, 1st-stage fixed gear, and 2 ndstage fixed gear. $T_{\text {in }}$ is the input and $T_{\text {out }}$ is the output.

2.1. Motion Differential Equations of the System. Based on the Lagrangian equation, the motion differential equations of the system are established on the basis of the clearance, the timevarying meshing stiffness, and the comprehensive meshing error $[7,8]$ :

$$
\begin{aligned}
J_{1} \ddot{\theta}_{1}+r_{1} F_{1} & =T_{\text {in }} \\
J_{23} \ddot{\theta}_{2}-r_{2} F_{1}+r_{3} F_{2} & =0 \\
J_{4 s} \ddot{\theta}_{4 s}+\sum_{n=1}^{4} r_{s} F_{s p n}-r_{4} F_{2} & =0 \\
J_{p n} \ddot{\theta}_{p n}-r_{p n} F_{s p n}+r_{p n} F_{r p n} & =0 \\
J_{c} \ddot{\theta}_{c}-\sum_{n=1}^{4} r_{c} F_{s p n}-\sum_{n=1}^{4} r_{c} F_{r p n} & =-T_{\text {out }},
\end{aligned}
$$

where $J_{23}=J_{2}+J_{3}, J_{4 s}=J_{4}+J_{s}: J_{1}, J_{2}, J_{3}, J_{4}, J_{s}, J_{p n}$, and $J_{c}$ are the moment of inertia of each gear on the shaft; $F_{1}, F_{2}, F_{s p n}$, and $F_{r p n}$ are the meshing force of each stage on the meshing line, $F_{i}=C_{i} \dot{x}_{i}+K_{i}(t) f\left(x_{i}\right)(i=1,2, s p n, r p n) ; x_{i}$ is the relative displacement of each stage meshing line $(i=1,2, s p n, r p n)$ :

$$
\begin{aligned}
x_{1} & =r_{1} \theta_{1}-r_{2} \theta_{2}-e_{1}(t), \\
x_{2} & =r_{3} \theta_{3}-r_{4} \theta_{4}-e_{2}(t), \\
x_{s p n} & =r_{s} \theta_{s}-r_{p n} \theta_{p n}-r_{c} \theta_{c}-e_{s p n}(t), \\
x_{r p n} & =r_{p n} \theta_{p n}-r_{c} \theta_{c}-e_{r p n}(t) ;
\end{aligned}
$$

$f\left(x_{i}\right)$ is the clearance nonlinear function $(i=1,2, s p n, r p n)$, written as

$$
f\left(\bar{x}_{i}\right)= \begin{cases}\bar{x}_{i}-b_{i}, & \bar{x}_{i}>b_{i} \\ 0, & \left|\bar{x}_{i}\right| \leq b_{i} \\ \bar{x}_{r p i}+b_{i}, & \bar{x}_{i}<-b_{i},\end{cases}
$$

where $b_{i}$ is half of the clearance $(i=1,2, s p n, r p n)$.

The time-varying meshing stiffness of the gear pair $K_{i}(t)$ will be specified in Section 2.2.

The damping coefficient forms

$$
\begin{aligned}
& C_{1}=2 \xi_{1} \sqrt{\frac{K_{m 1}}{\left(1 / m_{1}+1 / m_{2}\right)}} \\
& C_{2}=2 \xi_{2} \sqrt{\frac{K_{m 2}}{\left(1 / m_{3}+1 / m_{4}\right)}}
\end{aligned}
$$

$$
\begin{aligned}
& C_{s p n}=2 \xi_{s p n} \sqrt{\frac{K_{m s p n}}{\left(1 / m_{s}+1 / m_{p n}\right)}} \\
& C_{r p n}=2 \xi_{r p n} \sqrt{\frac{K_{m r p n}}{\left(1 / m_{r}+1 / m_{p n}\right)}},
\end{aligned}
$$

where $\xi_{1}, \xi_{2}, \xi_{s p n}$, and $\xi_{r p n}$ are damping ratios and $m_{1}, m_{2}, m_{3}$, $m_{4}, m_{s}, m_{p n}$, and $m_{r}$ are the mass of each gear.

The comprehensive meshing error of gear pair using the 1st harmonic form of meshing function is

$$
e_{i}(t)=e_{a i} \sin \left(w_{m i} t+\varphi_{i}\right),
$$

where $e_{a i}$ is the comprehensive meshing error amplitude of each gear $(i=1,2, s p n, r p n) . \varphi_{i}$ is the comprehensive meshing error initial phase of each gear $(i=1,2, s p n, r p n) ; w_{m i}$ is the meshing frequency of each gear $(i=1,2, s p n, r p n)$.

Define time nominal scale $w_{h}$, order $\tau=w_{h} t$, where $w_{h}=$ $\sqrt{K_{m 1} \times m_{e 1}} ; \bar{x}_{i}$ is dimensionless displacement, $\bar{x}_{i}=x_{i} / b_{1}$, $i=1,2, s p n, r p n ; \Omega_{i}$ is dimensionless excitation frequency, $\Omega_{i}=w_{m i} / w_{h}, i=1,2, s p n, r p n ; \bar{e}_{a i}$ is dimensionless comprehensive meshing error amplitude, $\bar{e}_{a i}=e_{a i} / b_{1}, i=1,2$, $s p n, r p n$. Dimensionless nonlinear function is

$$
f\left(\bar{x}_{i}\right)= \begin{cases}\bar{x}_{i}-\frac{b_{i}}{b_{1}}, & \bar{x}_{i}>\frac{b_{i}}{b_{1}} \\ 0, & \left|\bar{x}_{i}\right| \leq \frac{b_{i}}{b_{1}} \\ \bar{x}_{r p i}+\frac{b_{i}}{b_{1}}, & \bar{x}_{i}<-\frac{b_{i}}{b_{1}} .\end{cases}
$$

The equations are normalized, and the system dimensionless motion differential equations can be got:

$$
\begin{aligned}
& \ddot{\bar{x}}_{1}+\frac{C_{1}}{m_{e 1} w_{h}} \dot{\bar{x}}_{1}+\frac{K_{1}(\tau)}{m_{e 1} w_{h}^{2}} f\left(\bar{x}_{1}\right)-\frac{C_{2}}{m_{e 2} w_{h}} \dot{\bar{x}}_{2} \\
& \quad-\frac{K_{2}(\tau)}{m_{e 2} w_{h}^{2}} f\left(\bar{x}_{2}\right)=\frac{T_{\mathrm{in}} r_{1}}{J_{1} w_{h}^{2} b_{1}}+\frac{e_{a 1}}{b_{1}} \Omega_{1}^{2} \sin \left(\Omega_{1} \tau+\varphi_{1}\right) \\
& \ddot{\bar{x}}_{2}-\frac{C_{1}}{m_{e 1} w_{h}} \dot{\bar{x}}_{1}-\frac{K_{1}(\tau)}{m_{e 2} w_{h}^{2}} f\left(\bar{x}_{1}\right)+\frac{C_{2}}{m_{e 3} w_{h}} \dot{\bar{x}}_{2} \\
& +\frac{K_{2}(\tau)}{m_{e 3} w_{h}^{2}} f\left(\bar{x}_{2}\right)-\sum_{n=1}^{4} \frac{C_{s p n}}{m_{4 s} w_{h}} \dot{\bar{x}}_{s p n} \\
& \quad-\sum_{n=1}^{4} \frac{K_{s p n}(\tau)}{m_{4 s} w_{h}^{2}} f\left(\bar{x}_{s p n}\right)=\frac{e_{a 2}}{b_{1}} \Omega_{2}^{2} \sin \left(\Omega_{2} \tau+\varphi_{2}\right) \\
& \ddot{\bar{x}_{s p n}}+\frac{1}{m_{4 s} w_{h}} \sum_{n=1}^{4} C_{s p n} \dot{\bar{x}}_{s p n}+\frac{1}{m_{c} w_{h}} \sum_{n=1}^{4} C_{s p n} \dot{\bar{x}}_{s p n} \\
& \quad+\frac{1}{m_{p n} w_{h}} C_{s p n} \dot{\bar{x}}_{s p n}+\frac{1}{m_{4 s} w_{h}^{2}} \sum_{n=1}^{4} K_{s p n}(\tau) f\left(\bar{x}_{s p n}\right) \\
& \quad+\frac{1}{m_{c} w_{h}^{2}} \sum_{n=1}^{4} K_{s p n}(\tau) f\left(\bar{x}_{s p n}\right)
\end{aligned}
$$




$$
\begin{aligned}
& +\frac{1}{m_{p n} w_{h}^{2}} K_{s p n}(\tau) f\left(\bar{x}_{s p n}\right)-\frac{1}{m_{p n} w_{h}} C_{r p n} \dot{\bar{x}}_{r p n} \\
& +\frac{1}{m_{c} w_{h}} \sum_{n=1}^{4} C_{r p n} \dot{\bar{x}}_{r p n}-\frac{1}{m_{p n} w_{h}^{2}} K_{r p n}(\tau) f\left(\bar{x}_{r p n}\right) \\
& +\frac{1}{m_{c} w_{h}^{2}} \sum_{n=1}^{4} K_{r p n}(\tau) f\left(\bar{x}_{r p n}\right)-\frac{r_{4} C_{2}}{m_{4 s} r_{s} w_{h}} \dot{\bar{x}}_{2} \\
& -\frac{r_{4} K_{2}(\tau)}{m_{4 s} r_{s} w_{h}^{2}} f\left(\bar{x}_{2}\right)=\frac{r_{c} T_{\text {out }}}{J_{c e} w_{h}^{2} b_{1}} \\
& +\frac{e_{a s p n}}{b_{1}} \Omega_{s p n}^{2} \sin \left(\Omega_{s p n} \tau+\varphi_{s p n}\right) \\
& \ddot{\bar{x}}_{r p n}-\frac{1}{m_{p n} w_{h}} C_{s p n} \dot{\bar{x}}_{s p n}+\frac{1}{m_{c} w_{h}} \sum_{n=1}^{4} C_{s p n} \dot{\bar{x}}_{s p n} \\
& +\frac{1}{m_{p n} w_{h}^{2}} K_{s p n}(\tau)\left(\bar{x}_{s p n}\right) \\
& +\frac{1}{m_{c} w_{h}^{2}} \sum_{n=1}^{4} K_{s p n}(\tau) f\left(\bar{x}_{s p n}\right)+\frac{1}{m_{p n} w_{h}} C_{r p n} \dot{\bar{x}}_{r p n} \\
& \quad-\frac{1}{m_{c} w_{h}} \sum_{n=1}^{4} C_{r p n} \dot{\bar{x}}_{r p n}+\frac{1}{m_{p n} w_{h}^{2}} K_{r p n}(\tau) f\left(\bar{x}_{r p n}\right) \\
& \quad-\frac{1}{m_{c} w_{h}^{2}} \sum_{n=1}^{4} K_{r p n}(\tau) f\left(\bar{x}_{r p n}\right)=\frac{r_{c} T_{\text {out }}}{J_{c e} w_{h}^{2} b_{1}} \\
& +\frac{e_{a r p n}}{b_{1}} \Omega_{r p n}^{2} \sin \left(\Omega_{r p n} \tau+\varphi_{r p n}\right), \\
&
\end{aligned}
$$

where $m_{e 1}, m_{e 2}, m_{e 3}, m_{4 s}$ are the equivalent masses of gear; $J_{c e}$ is the equivalent moment of inertia of gear:

$$
\begin{aligned}
m_{e 1} & =\frac{J_{1} J_{23}}{J_{23} r_{1}^{2}+J_{1} r_{2}^{2}}, \\
m_{e 2} & =\frac{J_{23}}{r_{2} r_{3}} \\
m_{e 3} & =\frac{J_{4} J_{23}}{J_{23} r_{4}^{2}+J_{4} r_{3}^{2}}, \\
m_{4 s} & =\frac{J_{4 s}}{r_{s}^{2}} ; \\
J_{c e} & =J_{c}+N m_{p n} r_{c}^{2} .
\end{aligned}
$$

$$
\begin{aligned}
& K_{t} \\
& =\frac{1}{1 / k_{h}+1 / k_{b 1}+1 / k_{s 1}+1 / k_{a 1}+1 / k_{b 2}+1 / k_{s 2}+1 / k_{a 2}},
\end{aligned}
$$

2.2. Mesh Stiffness. The potential energy method [9] is used to evaluate the mesh stiffness with the consideration of Hertzian energy $k_{h}$, bending energy $k_{b}$, shear energy $k_{s}$, and axial compressive energy $k_{a}$. The beam model of a gear tooth is shown in Figure 2(a). The stiffness expressions are

$$
\begin{aligned}
& \frac{1}{k_{b}} \\
& =\frac{\left[1-(N-2.5) \cos \alpha_{1} \cos \alpha_{3} / N \cos \alpha_{0}\right]^{3}-\left(1-\cos \alpha_{1} \cos \alpha_{2}\right)^{3}}{2 E L \cos \alpha_{1} \sin ^{3} \alpha_{2}} \\
& \quad+\int_{-\alpha_{1}}^{\alpha_{2}} \frac{3\left\{1+\cos \alpha_{1}\left[\left(\alpha_{2}-\alpha\right) \sin \alpha-\cos \alpha\right]\right\}^{2}\left(\alpha_{2}-\alpha\right) \cos \alpha}{2 E L\left[\sin \alpha+\left(\alpha_{2}-\alpha\right) \cos \alpha\right]^{3}} d \alpha \\
& \frac{1}{k_{s}} \\
& =\frac{1.2(1+\nu) \cos ^{2} \alpha_{1}\left(\cos \alpha_{2}-\left((N-2.5) / N \cos \alpha_{0}\right) \cos \alpha_{3}\right)}{E L \sin \alpha_{2}} \\
& \quad+\int_{-\alpha_{1}}^{\alpha_{2}} \frac{1.2(1+\nu)\left(\alpha_{2}-\alpha\right) \cos \alpha \cos ^{2} \alpha_{1}}{E L\left[\sin \alpha+\left(\alpha_{2}-\alpha\right) \cos \alpha\right]} d \alpha \\
& \frac{1}{k_{a}} \\
& =\frac{\sin ^{2} \alpha_{1}\left(\cos \alpha_{2}-\left((N-2.5) / N \cos \alpha_{0}\right) \cos \alpha_{3}\right)}{2 E L \sin \alpha_{2}} \\
& \quad+\int_{-\alpha_{1}}^{\alpha_{2}} \frac{\left(\alpha_{2}-\alpha\right) \cos \alpha \sin ^{2} \alpha_{1}}{2 E L\left[\sin \alpha+\left(\alpha_{2}-\alpha\right) \cos \alpha\right]} d \alpha \\
& k_{h}=\frac{\pi E L}{4\left(1-v^{2}\right)},
\end{aligned}
$$

where $E$ represents the elastic modulus; $L$ is tooth width; $N$ is tooth number; $\alpha_{0}$ is the pressure angle; $\nu$ is Poisson's ratio.

2.2.1. Overall Mesh Stiffness. Gear tooth profile follows an involute curve up to the base circle as shown in Figure 2(a). The tooth profile between the base circle and the root circle is not an involute curve and hard to describe analytically [10]. Therefore, straight lines $N N^{\prime}$ and $D D^{\prime}$ are used to simplify the curve. For the single-tooth-pair meshing duration, the total effective mesh stiffness can be calculated as [11]

where subscripts 1 and 2 represent the driving gear and the driven gear, respectively.

For the double-tooth-pair meshing duration, there are two pairs of gears meshing at the same time. Total effective mesh stiffness can be obtained as [11]

$$
K_{t}=K_{t 1}+K_{t 2}=\sum_{j=1}^{2} \frac{1}{1 / k_{h, j}+1 / k_{b 1, j}+1 / k_{s 1, j}+1 / k_{a 1, j}+1 / k_{b 2, j}+1 / k_{s 2, j}+1 / k_{a 2, j}},
$$

where $j=1$ for the 1st pair and $j=2$ for the 2nd pair of meshing teeth.
2.2.2. Crack Modeling. The crack is modeled as a straight line from the gear tooth danger area (Figure 2(b)). The crack 


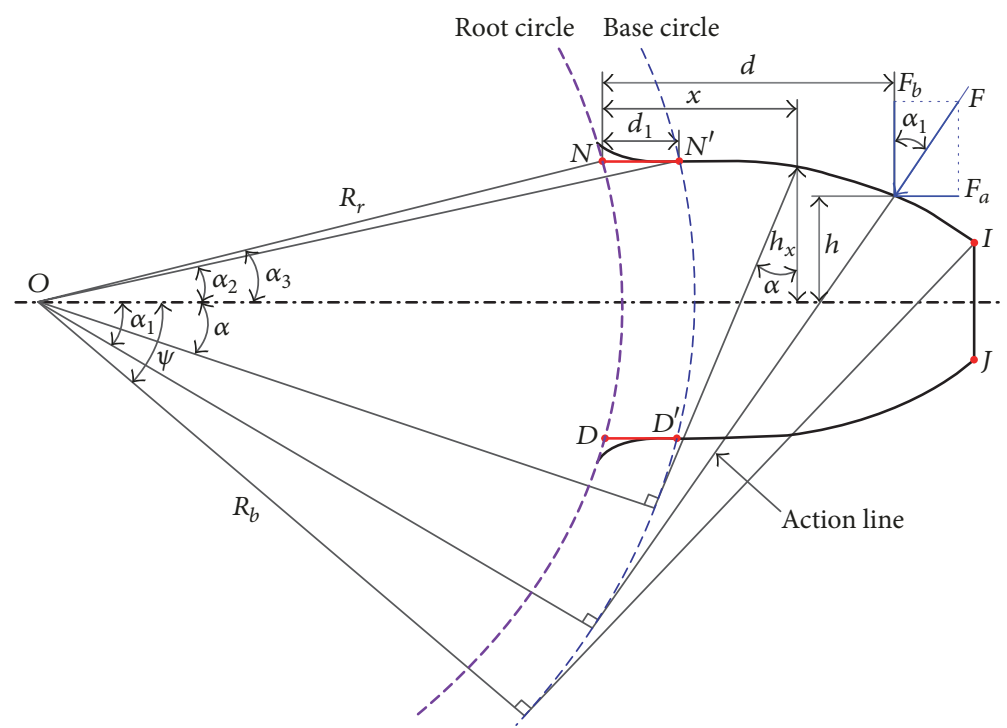

(a)

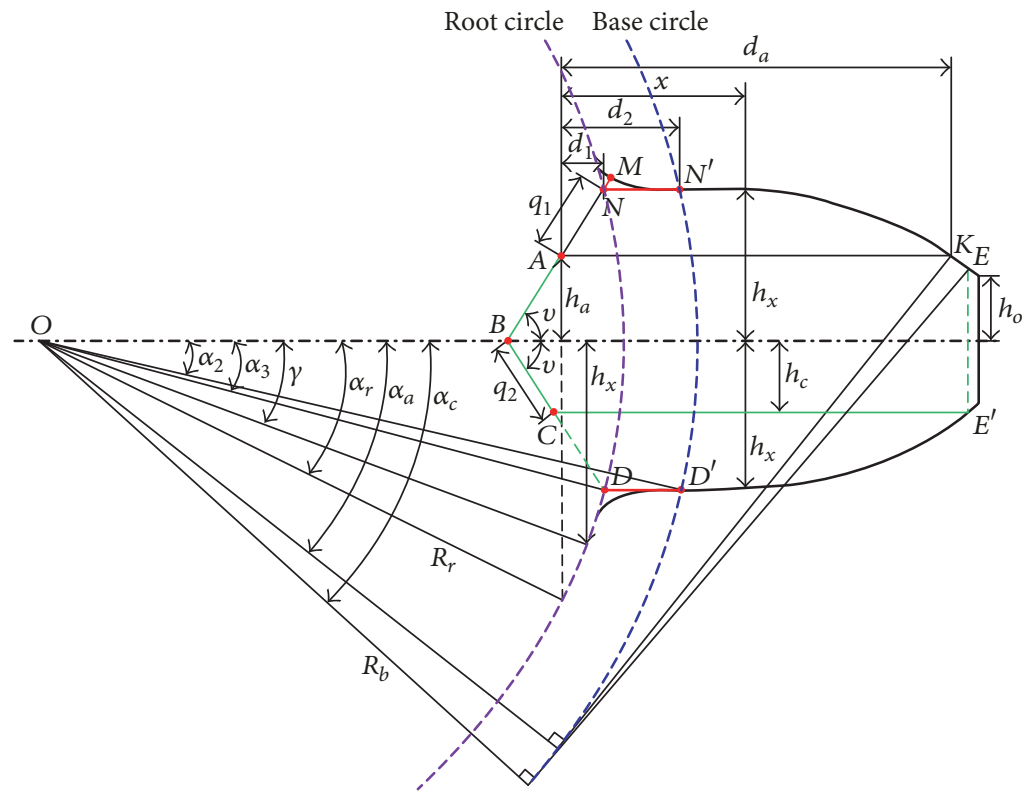

(b)

FiguRE 2: Beam model of an external gear tooth: (a) beam model and (b) cracked tooth model [9].

propagates along the straight line until reaching the tooth central line at point $B$. Then, it changes the propagation direction towards point $D$ where the tooth breaks. According to the state of the crack in the test rig, only the state when the crack does not reach the centerline is studied, where $q_{1}$ is the crack length and the angle between the crack line and the tooth center line is defined as $v$.
The Hertzian stiffness and axial compressive stiffness will not be affected by the crack propagation [10]. Only the bending stiffness and the shear stiffness will be affected due to the change in the tooth length and the tooth height caused by the crack. The bending stiffness and the shear stiffness with the crack fault are

$$
\begin{aligned}
\frac{1}{k_{b}}= & \int_{\alpha_{3}}^{\alpha_{r}} \frac{12 \sin \alpha\left[N \cos \alpha_{0} /(N-2.5)-\left(\cos \alpha+\cos \alpha_{3}-\cos \alpha_{r}-\left(q_{1} / R_{r}\right) \cos v\right) \cos \alpha_{1}\right]^{2}}{E L\left(\sin \alpha_{3}+\sin \alpha-\left(q_{1} / R_{r}\right) \sin v\right)^{3}} d \alpha \\
& +\frac{4\left[1-(N-2.5) \cos \alpha_{1} \cos \alpha_{3} / N \cos \alpha_{0}\right]^{3}-4\left(1-\cos \alpha_{1} \cos \alpha_{2}\right)^{3}}{E L \cos \alpha_{1}\left(2 \sin \alpha_{2}-\left(q_{1} / R_{b}\right) \sin v\right)^{3}}
\end{aligned}
$$


TABLE 1: Gear parameters.

\begin{tabular}{|c|c|c|c|c|c|c|c|c|}
\hline Gear & Number of teeth & $R_{r i} / \mathrm{mm}$ & $R_{b i} / \mathrm{mm}$ & Mass $m_{i} / \mathrm{g}$ & $J_{i} /\left(\mathrm{g} \cdot \mathrm{m}^{2}\right)$ & Face width/mm & Module/mm & Wheel axle distance $/ \mathrm{mm}$ \\
\hline 1 & 29 & 19.2 & 20.4 & 125 & 0.05 & 30 & 1.5 & \multirow{2}{*}{91.318} \\
\hline 2 & 100 & 68.9 & 70.5 & 1224.5 & 6 & 30 & 1.5 & \\
\hline 3 & 36 & 23.9 & 25.3 & 224 & 0.14 & 30 & 1.5 & \multirow{6}{*}{90.8304} \\
\hline 4 & 90 & 61.5 & 63.4 & 1111 & 4 & 20 & 1.5 & \\
\hline$s$ & 28 & 12.3 & 13 & 41 & 0.007 & 20 & 1.0 & \\
\hline$p n$ & 36 & 16 & 17 & 34.6 & 0.01 & 20 & 1.0 & \\
\hline$c$ & & & 30 & 848.7 & 0.76 & 20 & 1.0 & \\
\hline$r$ & 100 & 45.6 & 47 & & & 20 & 1.0 & \\
\hline
\end{tabular}

$$
\begin{aligned}
& +\int_{-\alpha_{1}}^{\alpha_{2}} \frac{12\left\{1+\cos \alpha_{1}\left[\left(\alpha_{2}-\alpha\right) \sin \alpha-\cos \alpha\right]\right\}^{2}\left(\alpha_{2}-\alpha\right) \cos \alpha}{E L\left[\sin \alpha_{2}-\left(q_{1} / R_{b}\right) \sin v+\sin \alpha+\left(\alpha_{2}-\alpha\right) \cos \alpha\right]^{3}} d \alpha \\
\frac{1}{k_{s}}= & \int_{\alpha_{3}}^{\alpha_{r}} \frac{2.4(1+\nu) \cos ^{2} \alpha_{1} \sin \alpha}{E L\left(\sin \alpha_{3}-\left(q_{1} / R_{r}\right) \sin v+\sin \alpha\right)^{3}} d \alpha+\frac{2.4(1+\nu) \cos ^{2} \alpha_{1}\left(\cos \alpha_{2}-\left((N-2.5) / N \cos \alpha_{0}\right) \cos \alpha_{3}\right)}{E L\left(2 \sin \alpha_{2}-\left(q_{1} / R_{b}\right) \sin v\right)} \\
& +\int_{-\alpha_{1}}^{\alpha_{2}} \frac{2.4(1+\nu)\left(\alpha_{2}-\alpha\right) \cos \alpha \cos ^{2} \alpha_{1}}{E L\left[\sin \alpha_{2}-\left(q_{1} / R_{b}\right) \sin v+\sin \alpha+\left(\alpha_{2}-\alpha\right) \cos \alpha\right]} d \alpha .
\end{aligned}
$$

Calculate the bending and shear stiffness of the cracked tooth, and then calculate the overall mesh stiffness of the cracked tooth by (11). In this study, we assume that the 1ststage fixed-axis small gear (spur gear 1 ) has a crack fault. The crack gear in test rig is shown in Figure 3 (crack length $q_{1}=$ $1 \mathrm{~mm}$, crack angle $v=70^{\circ}$ ). The time-varying meshing stiffness is calculated when the speed is $1 \mathrm{~Hz}$ (Figure 4). The gear parameters of gear transmission system are shown in Table 1.

2.2.3. Wear Model. The gap between the teeth is altered when the wear occurs. When the gears are evenly worn, the gap between the teeth of the faulted gears will be increased. Therefore all tooth wear fault can be expressed in terms of constants. The function is

$$
f\left(\bar{x}_{i}\right)= \begin{cases}\bar{x}_{i}-(1+a), & \bar{x}_{i}>(1+a) \\ 0, & \left|\bar{x}_{i}\right| \leq 1 \\ \bar{x}_{i}+(1+a), & \bar{x}_{i}<-(1+a),\end{cases}
$$

where parameter $a$ is the size of all tooth wear. Assuming that there is all tooth wear fault in the planetary gear 1 , the gear shown in Figure 5 is a planetary gear with all tooth wear fault in the test rig of this paper, and its fault feature is set to $a=0.1$.

\section{Analysis of Nonlinear Dynamic Behavior of Coupling Fault}

3.1. System Bifurcation Diagrams. The bifurcation diagrams with the excitation frequency changed are calculated, respectively, when the system is in normal state, planetary gear wear fault state, and the fixed-axis crack fault state, and two faults coexist. The structure parameters of the system are shown in Tables 1 and 2, pressure angle $\alpha_{0}=20^{\circ}, T_{\text {in }}=6.5 \mathrm{~N} \cdot \mathrm{m}$, and $T_{\text {out }}$ $=8.5 \mathrm{~N} \cdot \mathrm{m}$. The values in Table 2 are equal on the meshing line of gear, so the subscript $i$ is omitted.

Due to the fact that there are a lot of side frequencies at the meshing point of the 1st-stage fixed-axis gear, so as to study the bifurcation of this point, the nonlinear differential equations (7) are numerically solved using the variable step Runge-Kutta method to obtain the bifurcation diagram of the relative displacement of the 1st-stage fixed-axis gear in four states with the dimensionless excitation frequency $\Omega_{1}$ changed (Figure 6).

In (7), it can be seen that all stages of gears are affected not only by their own vibration characteristics, but also by the influence of adjacent teeth on the vibration characteristics. Therefore, when using variable step Runge-Kutta method for iterative calculation of coupling faults, the fault features of the planetary gear wear fault are transmitted to the 2ndstage fixed-axis gear through the velocity and displacement of the planetary gear and the sun gear meshing point and then transmitted to the 1st-stage fixed-axis gear which has two kinds of faults (the planetary gear wear fault and the 1st-stage fixed-axis crack). The two faults can interact and then show the coupling effect.

When the excitation frequency is small in normal state, the motion state of the 1st-stage fixed-axis gear is periodic (Figure 6(a)). When the excitation frequency increases to 0.5 , the system becomes with quasiperiodic motion by periodic motion. When the excitation frequency increases to 1 (critical rotational speed), the system resonates and the motion becomes chaotic. Then the system is divided into three times periodic motion and finally into the quasiperiodic motion. 
TABLE 2: Parameters of calculation.

\begin{tabular}{lc}
\hline Parameters of calculation & Value \\
\hline Gear clearance $b(\mu \mathrm{m})$ & 5 \\
Comprehensive meshing error amplitude $e_{a}(\mu \mathrm{m})$ & 5 \\
Meshing pair damping ratio $\xi$ & 0.07 \\
Gear contact ratio & 1.68 \\
\hline
\end{tabular}

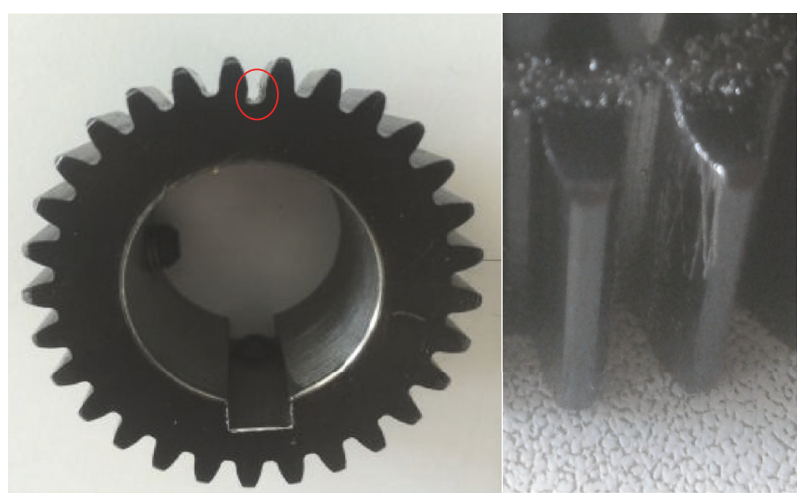

Figure 3: Fixed-axis gear with crack.

Figure 6 shows that when the system only has a fixedaxis crack fault, it has an effect on the period, the quasiperiod, and the 3 times periodic motion when the excitation frequency is less than 3. That is, fault periodic motion is increased in the original periodic motion, indicating that the fixed-axis crack fault is sensitive to low speed. In actual operation, the motor speed is usually a low speed. This creates the fixed-axis fault which is easy to identify, and the planetary gear fault is difficult to identify.

When the system only has the planetary gear wear fault, the quasiperiodic motion with excitation frequency greater than 3 (3 times critical speed) becomes the intermittent periodic motion, indicating that the planetary gear wear fault is sensitive to the high speed.

When the system has the coupling fault, the fault characteristics are similar to single fixed-axis crack fault when the excitation frequency is less than 3 , and the fault characteristics are similar to single planetary gear wear fault when the excitation frequency is greater than 3. Planetary fault and fixed-axis fault affect different speed, so the vibration coupling phenomenon of the two on the bifurcation diagram is not obvious. Since the mutual influence of the coupling fault cannot be found from the bifurcation diagram, it is necessary to further study the fault frequency characteristics caused by the coupling fault.

3.2. Coupling Fault Frequency Characteristics. The fault characteristics of the fixed-axis crack fault in low excitation frequency have been described in the literature [6]. This paper will study the planetary wear fault at high excitation frequency. The vibration is obvious in the interval of $\Omega_{1}=$ $[3.5,5]$. So this part will be studied. The time domain, frequency domain, phase diagram, and Poincaré section of the 1st-stage fixed-axis gear are shown in Figure 7 in the

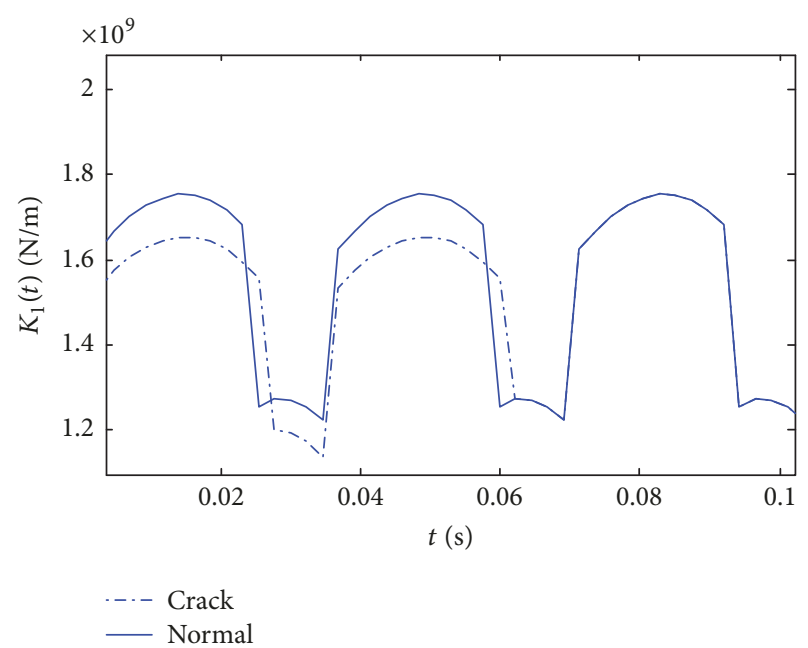

FIGURE 4: The meshing stiffness of the fixed-axis gear with crack.

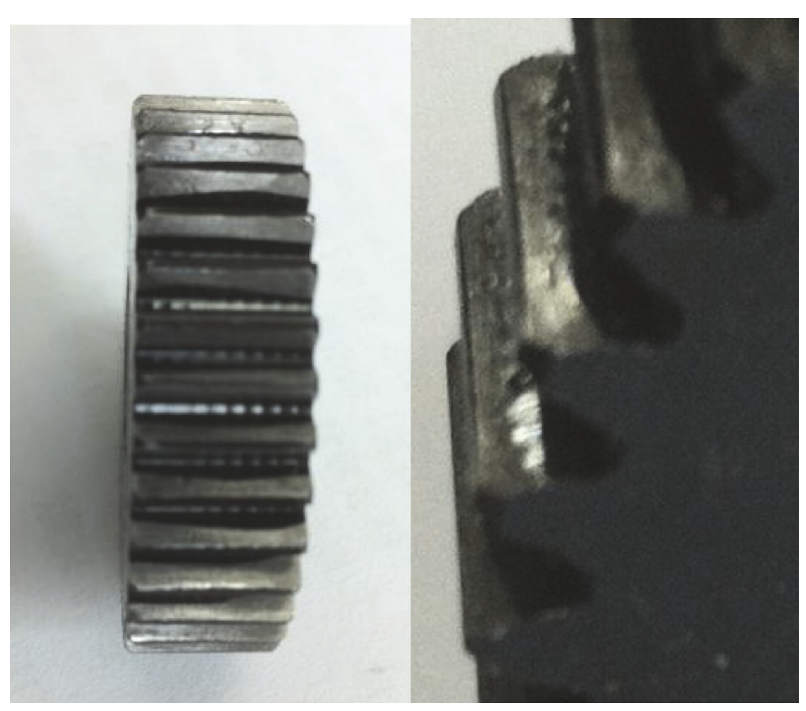

FIgURE 5: Planetary gear with wear fault.

normal state, the fixed-axis crack state, and the coupling fault state of fixed-axis crack + planetary wear, when the excitation frequency is 3.5. Dimensionless characteristic frequencies of gear transmission system at all stages are shown in Table 3.

There is an increase in the impact of fault in the time domain (Figures $7(a), 8(a)$, and $9(a)$ ) as the number of faults increases. The phase diagram behaves as quasiperiodic motion bands in the normal state (Figure 7(b)), and the band becomes wider in crack fault state (Figure $8(\mathrm{~b})$ ). When a coupling fault occurs, the fault cycle makes the band full (Figure 9(b)). The point group of the Poincaré section (Figures 7(c), 8(c), and 9(c)) also increases with the increase of fault. The amplitude of the coupling fault in frequency domain (Figures 7(d), 8(d), and 9(d)) increases significantly.

Figures $7(\mathrm{e}), 8(\mathrm{e})$, and $9(\mathrm{e})$ are the spectral refinement of Figures $7(\mathrm{~d}), 8(\mathrm{~d})$, and $9(\mathrm{~d})$, at low frequencies. It can be seen from Figure $7(\mathrm{e})$ that the main peak of the system is the meshing frequency of 1st-stage fixed-axis gear $f_{1}$, the 


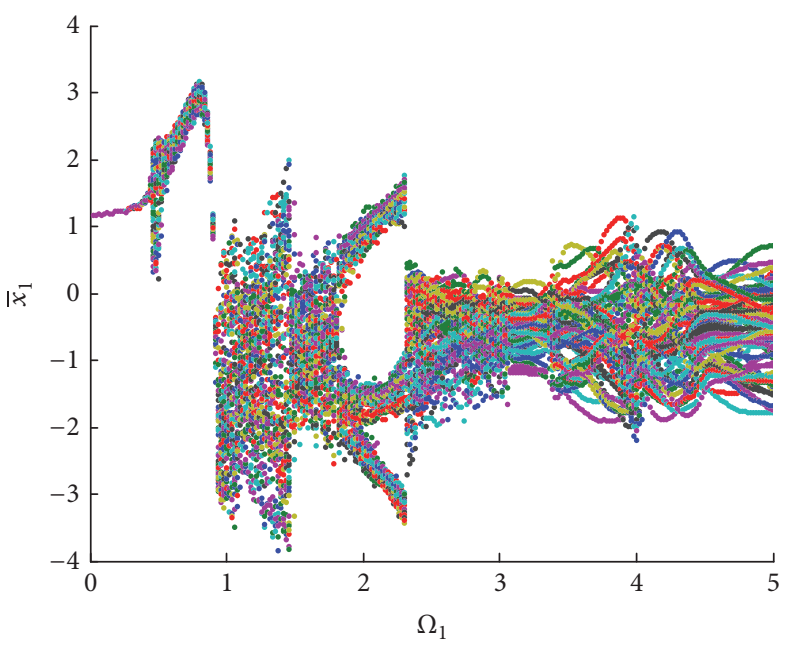

(a)

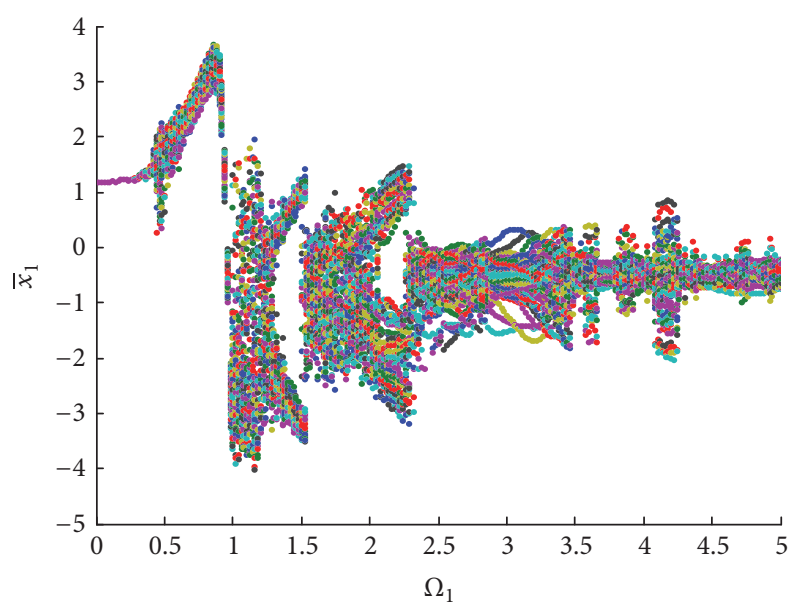

(c)

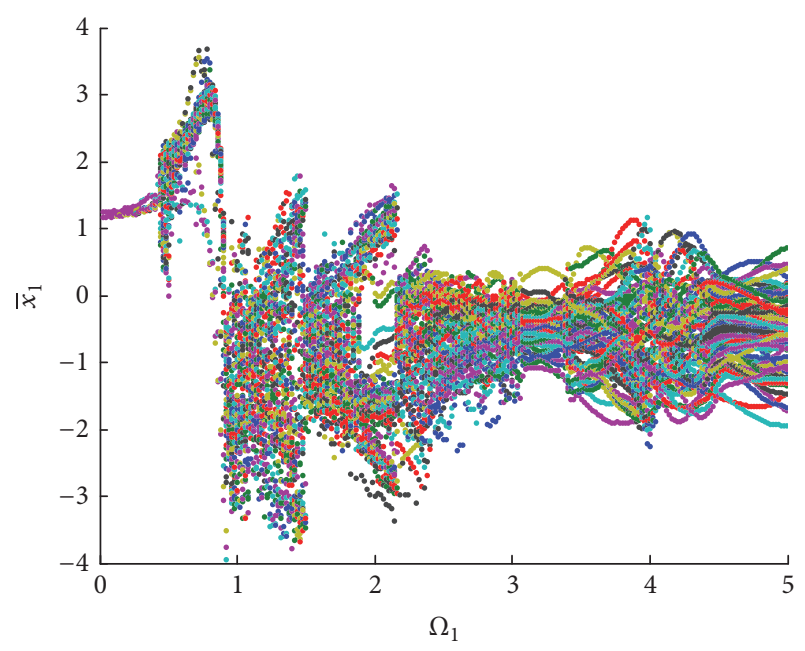

(b)

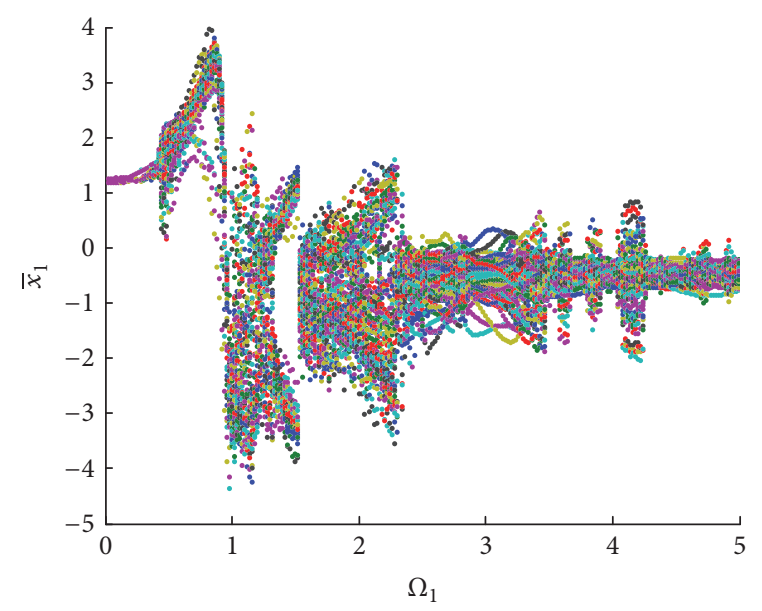

(d)

FIGURE 6: Displacement bifurcation diagram of the first fixed gear: (a) normal state, (b) fixed-axis crack, (c) planetary wear, and (d) two-fault coupling.

TABLE 3: Dimensionless characteristic frequencies of gear transmission system $(\mathrm{Hz})$.

Meshing frequency of 1st-stage fixed-axis gear $f_{1}$

Meshing frequency of 2nd-stage fixed-axis gear $f_{2}$

meshing frequency of 2nd-stage fixed-axis gear $f_{2}$, the meshing frequency of the planetary gear $f_{3}$, and its double and triple $\left(2 f_{3}, 3 f_{3}\right)$ in normal state. There are a large number of regular side frequencies around the meshing frequency of the planetary gear and its double and triple. The side frequency is the rotation frequency of the 2 nd-stage rotating shaft $f_{d}$. It can be seen from Figure 8(e) that the fault frequency of the fixed-axis crack $f_{d}$ occurs at a peak value of $1 \sim 10$ times, and the amplitude gradually decreases. Figure $9(\mathrm{e})$ shows that the increase of planetary gear wear fault makes the amplitude of the planetary gear meshing frequency and its double and triple increased. So two kinds of fault characteristics occur at the same time in coupling faults state, all around the planet gear meshing frequency.

\section{Experimental Failure Analysis}

The test rig of gear transmission system which contains a twostage fixed-axis gear and a one-stage planetary is shown in Figure 10. The parameters are shown in Tables 1 and 3. Test and analyze the signal of the test rig in normal state and coupling faults state, in which the crack failure occurs on 


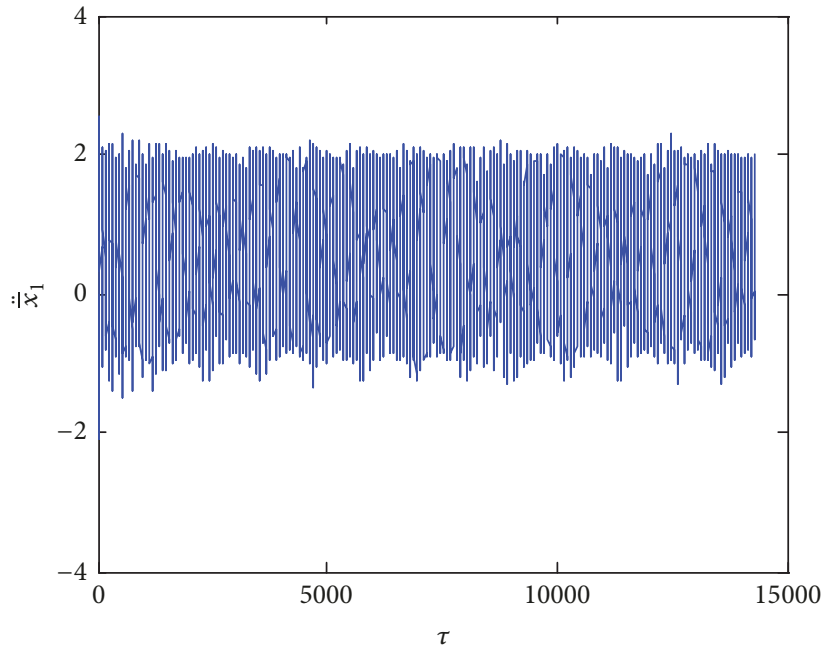

(a)

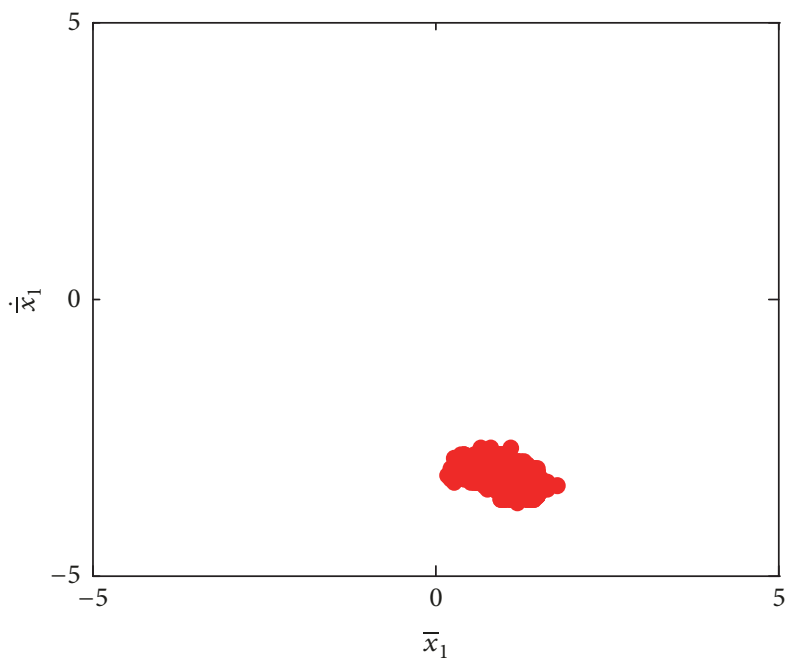

(c)

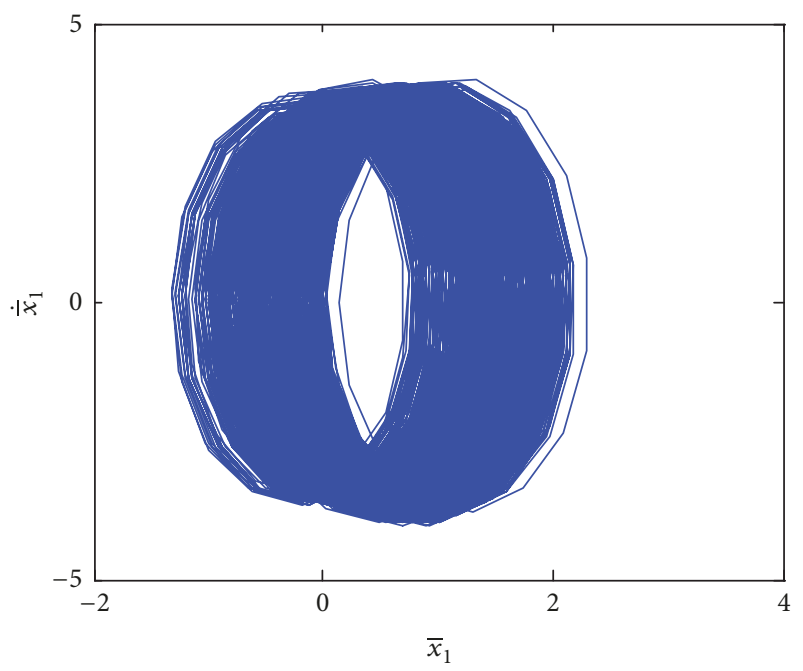

(b)

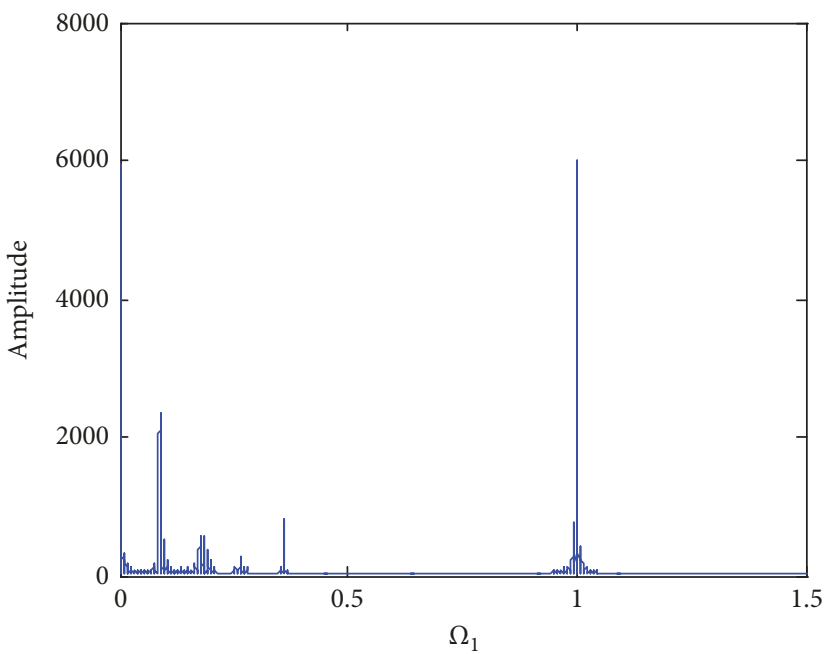

(d)

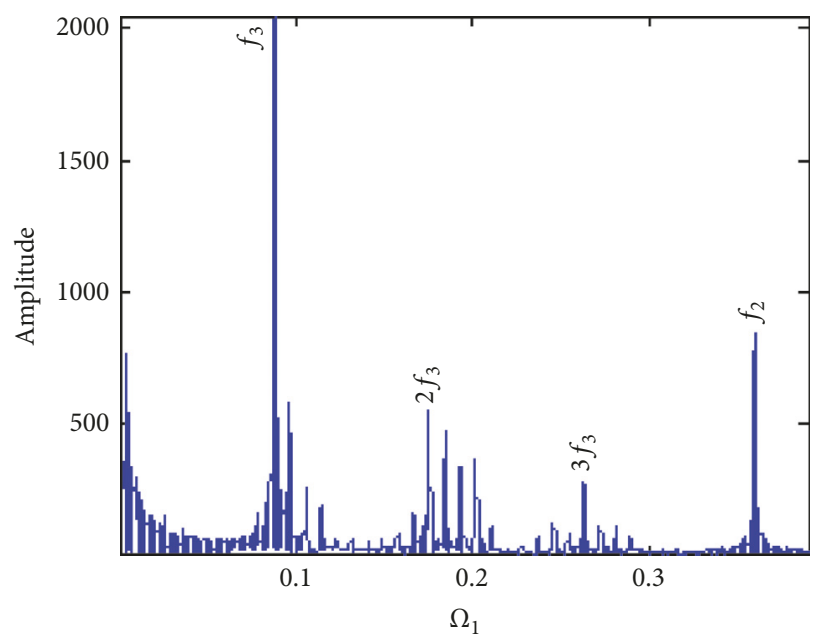

(e)

Figure 7: Vibration characteristics when the excitation frequency is 3.5 in normal state: (a) time domain, (b) phase diagram, (c) Poincaré section, (d) frequency domain, and (e) frequency refinement spectrum. 


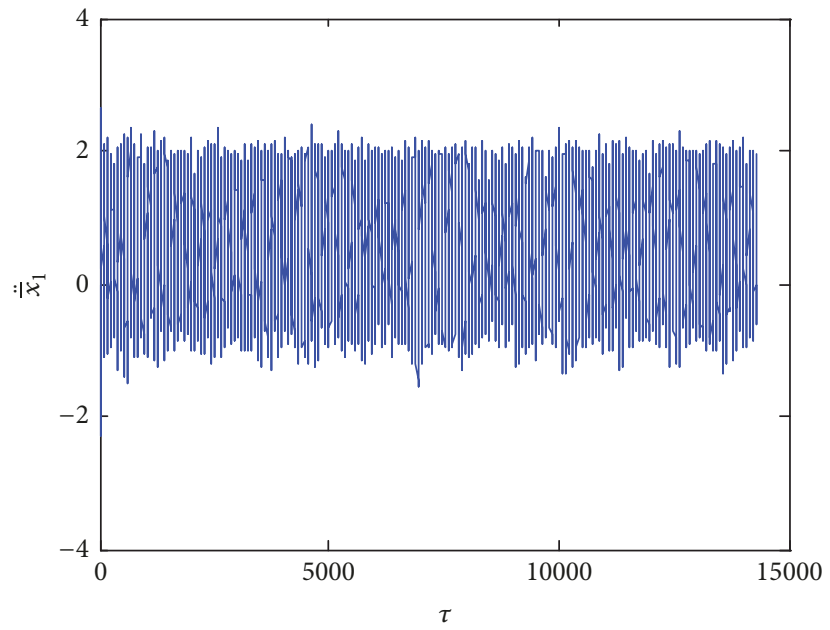

(a)

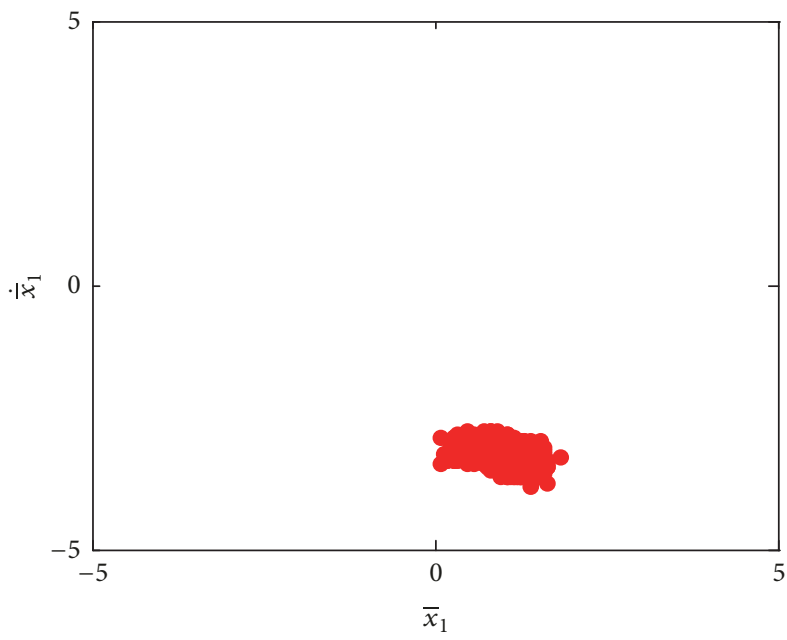

(c)

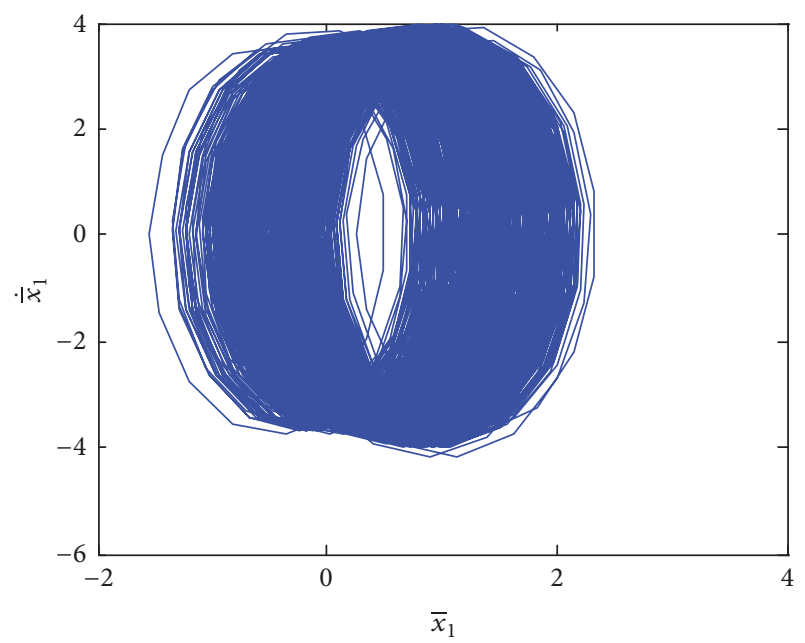

(b)

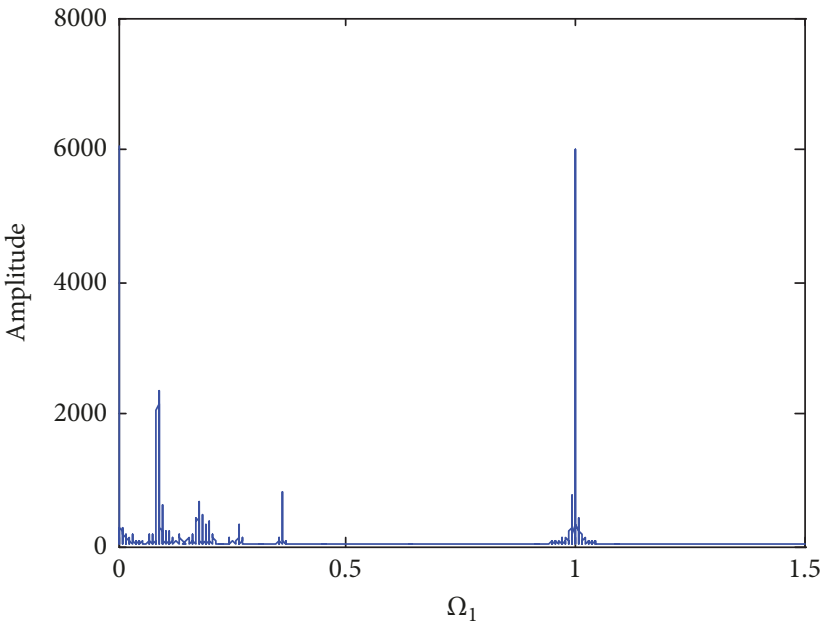

(d)

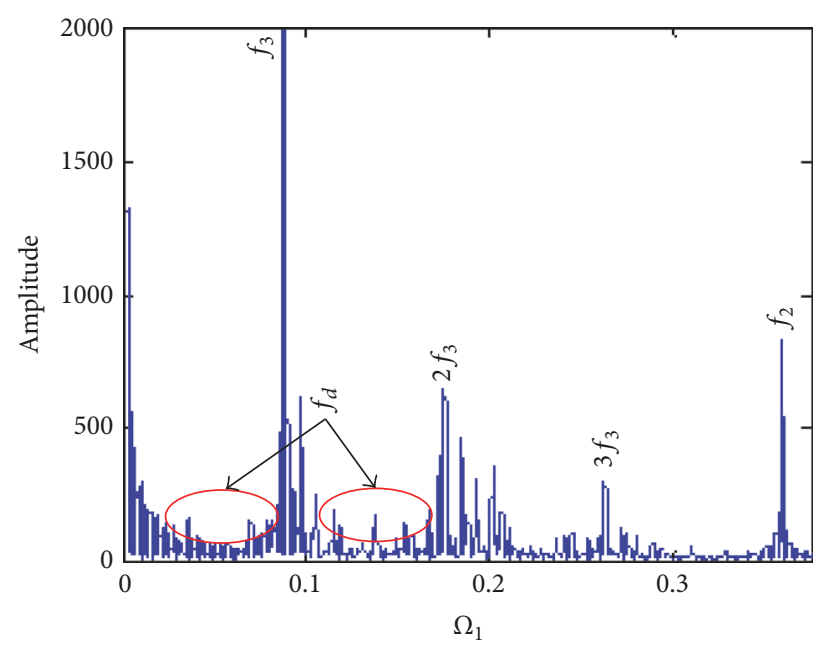

(e)

FIGURE 8: Vibration characteristics when the excitation frequency is 3.5 in fixed-axis crack state: (a) time domain, (b) phase diagram, (c) Poincaré section, (d) frequency domain, and (e) frequency refinement spectrum. 


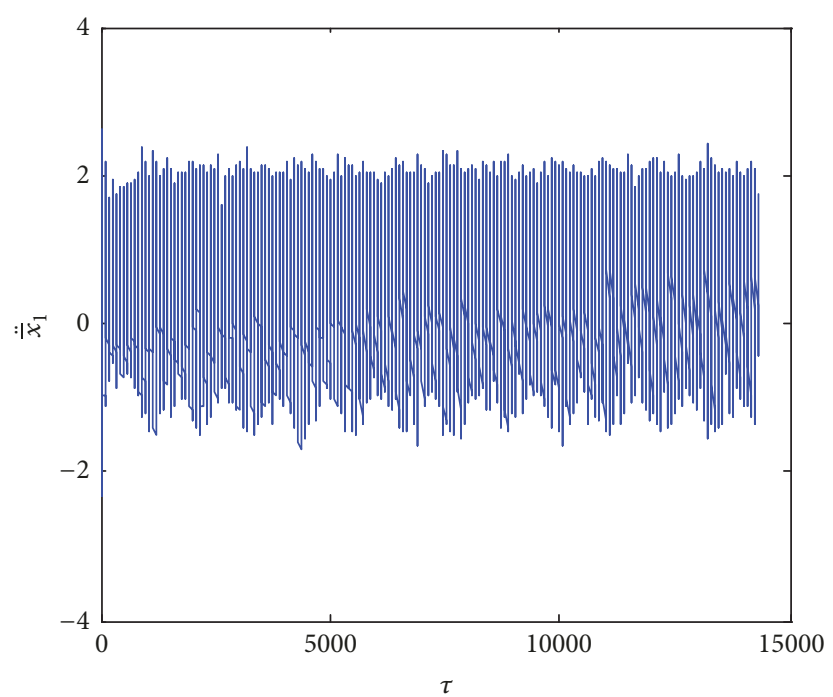

(a)

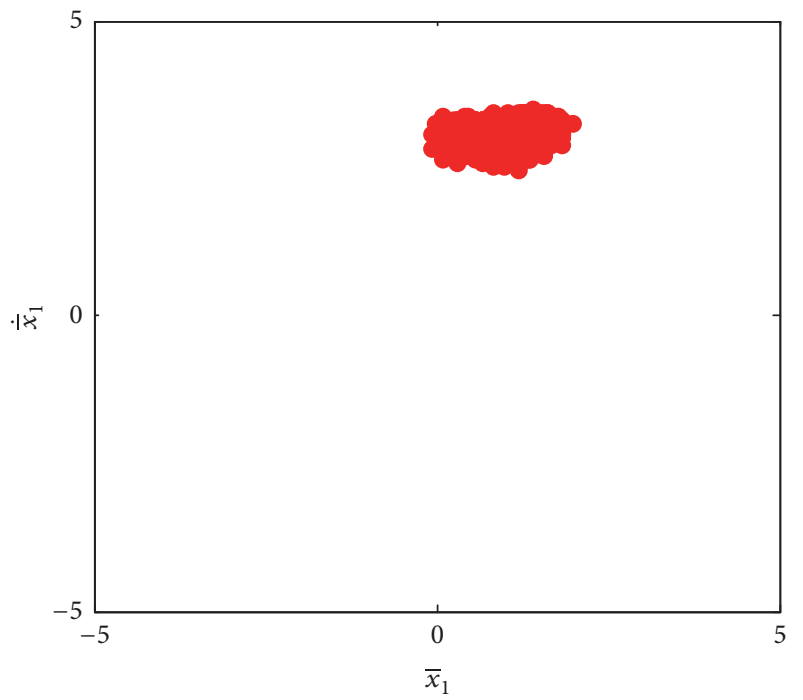

(c)

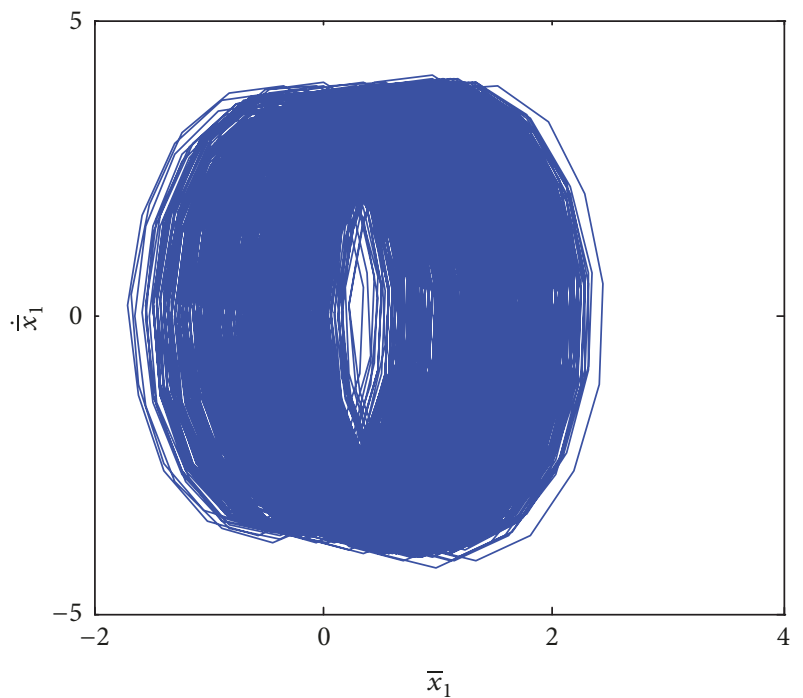

(b)

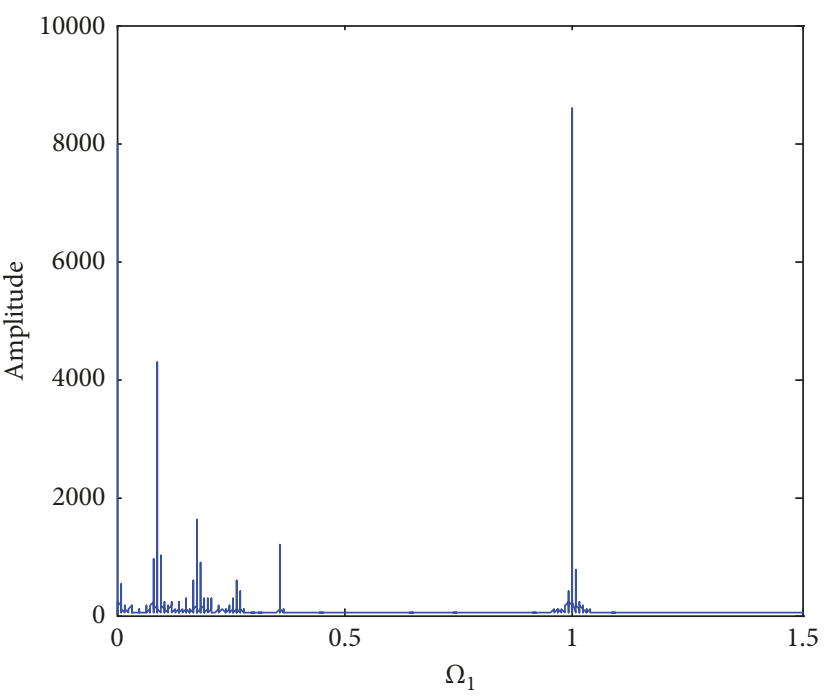

(d)

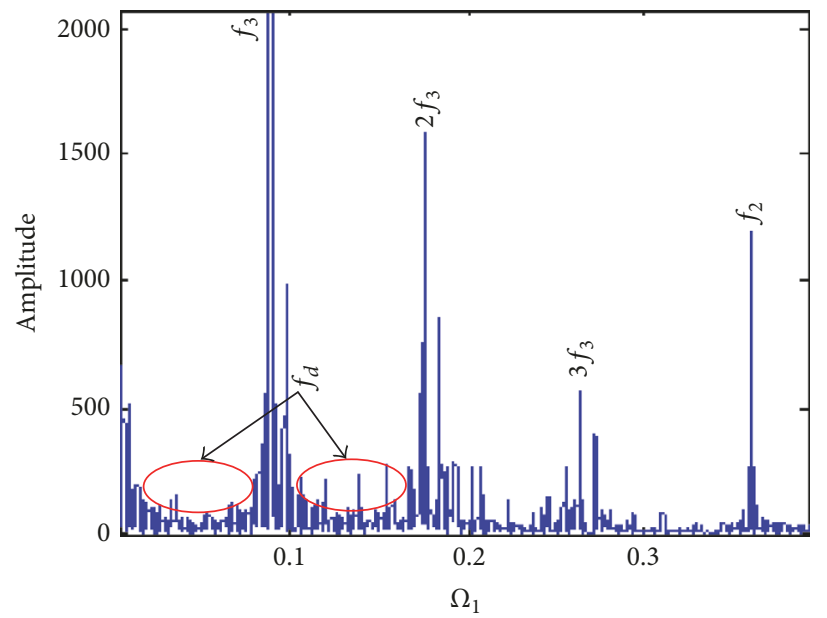

(e)

FIGURE 9: Vibration characteristics when the excitation frequency is 3.5 in coupling faults state: (a) time domain, (b) phase diagram, (c) Poincaré section, (d) frequency domain, and (e) frequency refinement spectrum. 


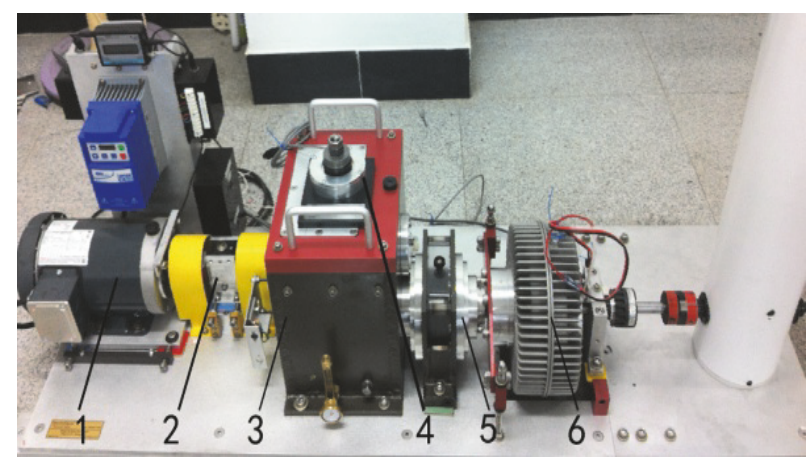

Figure 10: The test rig of gear transmission system: 1: motor; 2: torque sensor and encoder; 3: two-stage fixed-axis gearbox; 4: radial load of bearing; 5: one-stage planetary gearbox; 6: brake.

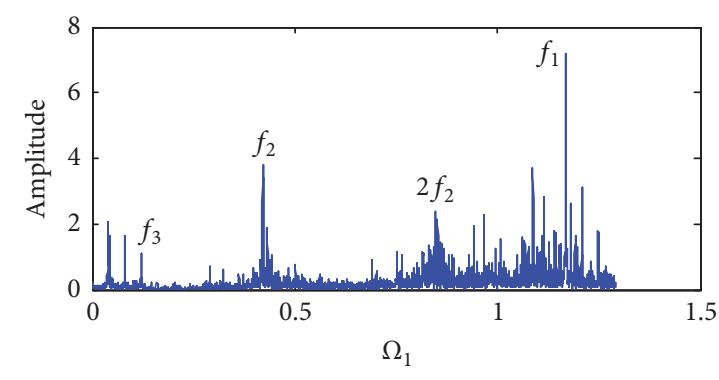

(a)

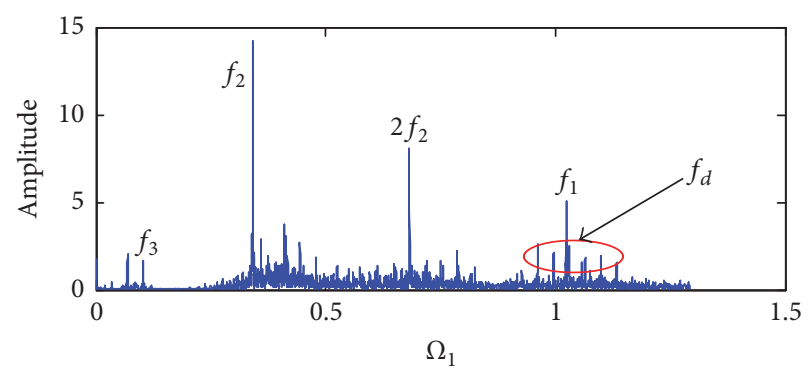

(b)

FIGURE 11: Spectrum of the fixed-axis gearbox: (a) normal state and (b) coupling faults of fixed-axis gear crack and planetary wear.

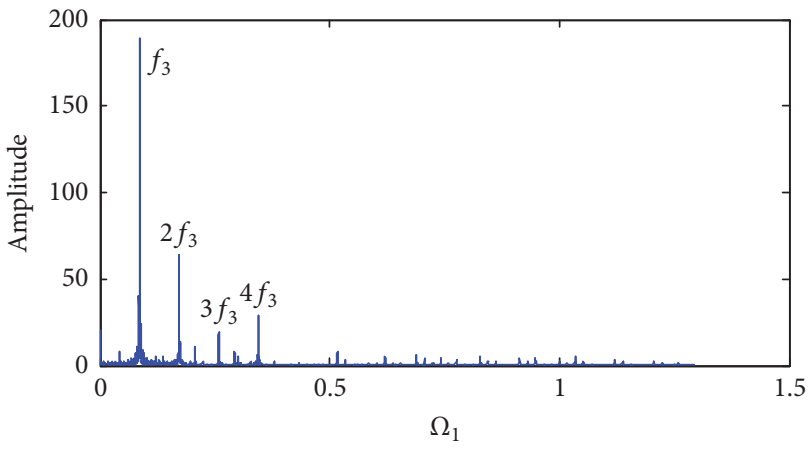

(a)

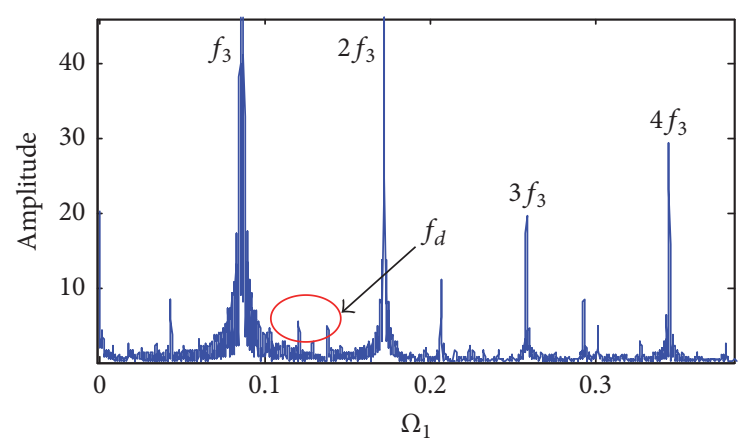

(b)

FIGURE 12: Spectrum of the planetary gearbox with the coupling faults of fixed-axis gear crack and planetary gear wear: (a) frequency domain and (b) frequency refinement spectrum.

the 1st-stage pinion (spur gear 1 in Figure 1) with the crack length $q_{1}=1 \mathrm{~mm}$ and the crack angle $v=70^{\circ}$, as shown in Figure 3. Planetary wear fault occurs in the first planetary gear $p 1$ in Figure 1, and the planetary gear wear parameter is $a=0.1$ (Figure 5). Sampling frequency is $3000 \mathrm{~Hz}$, the number of sampling points is 2048, and the axial measurement points of the fixed-axis gearbox drive side are selected for testing. In order to facilitate the comparison, the spectrums are normalized to get the dimensionless spectrum in normal state and coupling faults state (Figure 11).

The amplitude of the 2nd-stage fixed-axis meshing frequency $f_{2}$ and its doubling $2 f_{2}$ increased in the coupling faults state (Figures 11(a) and 11(b)). Around the fixed-axis gear meshing frequency $f_{1}$ appears a large amount of fixedaxis fault characteristic frequency $f_{d}$. But the amplitude of the planetary gear meshing frequency $f_{3}$ is relatively weak, and the surrounding frequency is not easy to identify. So the dimensionless radial spectrum of the planetary gearbox under the coupling faults state is investigated, as shown in Figure 12.

The amplitude of planetary gear meshing frequency $f_{3}$ and its frequency-doubling $\left(2 f_{3}, 3 f_{3}\right.$, and $\left.4 f_{3}\right)$ in vibration signals of the planetary gearbox greatly increased (Figures 12 and 11). As can be seen in the frequency refinement diagram 
near the frequency of the planetary gear, the fault frequency of the fixed axis $f_{d}$ is found around $f_{3}$, which is consistent with the numerical simulation results. By observing the vibration signal of the fixed-axis gearbox and the planetary gearbox, the fixed-axis crack fault and the planetary gear wear fault were identified.

\section{Conclusion}

In this study, dimensionless dynamical equations of gear transmission system which contains a two-stage fixed-axis gear with crack fault and a one-stage planetary gear with wear fault were established. With contrasted bifurcation and frequency spectrum characteristics of system in normal condition and coupling faults condition, it found that when the system has the coupling fault, the fault characteristics are similar to single fixed-axis crack fault when the excitation frequency is less than 3 , and the fault characteristics are similar to single planetary gear wear fault when the excitation frequency is greater than 3 . This paper studied the planetary wear fault at high excitation frequency. Fault frequency characteristics caused by the coupling faults of the fixed-axis crack fault and the planetary gear wear fault were analyzed. Simulation analysis shows that the crack fault in fixed-axis gear brings up peaks in doubling of 1 10 for fault frequency, the wear fault in planetary gear increases the amplitude of meshing frequency and its double and triple, and the coupling of both shows two kinds of fault features around the planetary gear meshing frequency. For the test rig, by observing the vibration signal of the fixed-axis gearbox and the planetary gearbox, it is found that the experimental characteristics are consistent with the numerical simulation results. Through numerical simulation results the fixed-axis crack fault and the planetary gear wear fault are accurately identified. This study explored the complex fault features in multistage gear transmission system and cognized fault dynamic behaviors of multistage gear transmission system comprehensively to diagnose the complex fault of multistage gear accurately.

\section{Conflicts of Interest}

The author declares that there are no conflicts of interest regarding the publication of this paper.

\section{Acknowledgments}

The author gratefully acknowledges the financial support from the Key Project of Baoji University of Arts and Sciences (no. 209010861).

\section{References}

[1] Z. Li, X. Yan, Z. Tian, C. Yuan, Z. Peng, and L. Li, "Blind vibration component separation and nonlinear feature extraction applied to the nonstationary vibration signals for the gearbox multi-fault diagnosis," Measurement, vol. 46, no. 1, pp. 259-271, 2013.

[2] Z. Li, X. Yan, C. Yuan, J. Zhao, and Z. Peng, "The fault diagnosis approach for gears using multidimensional features and intelligent classifier," Noise \& Vibration Worldwide, vol. 41, no. 10, pp. 76-86, 2010.

[3] Z. Li, "A novel solution for the coupled faults isolation in gear pairs using the conception of frequency tracking," Elektronika ir Elektrotechnika, vol. 20, no. 3, pp. 69-72, 2014.

[4] C. Luo, C. Shen, W. Fan, G. Cai, W. Huang, and Z. Zhu, "Research on the sparse representation for gearbox compound fault features using wavelet bases," Shock and Vibration, vol. 2015, Article ID 560171, 2015.

[5] L. Xiao-yu, X. Yu-xiu, and X. Gang, "Nonlinear characteristics of complex and weak faults of planetary gear transmission system," Mechanical Science and Technology for Aerospace Engineering, vol. 34, no. 4, pp. 538-543, 2013.

[6] X. Wang, X. Y. Xu, and B. L. Wu, "Study on failure characteristics of gearbox transmission system with coupling faults," Journal of Vibration, vol. 36, no. 12, pp. 217-223, 2017.

[7] D. Qin, W. Long, J. Yang, and H. Zhou, "Dynamic characteristics of wind turbine transmission system under verying wind speed and operation control conditions," Jixie Gongcheng Xuebao/Journal of Mechanical Engineering, vol. 48, no. 7, pp. 1-8, 2012.

[8] D. Qin, M. Tian, and J. Yang, "Study on dynamic characteristics of gear transmission system of wind generator under varying wind load," Acta Energiae Solaris Sinica, vol. 33, no. 2, pp. 190196, 2012.

[9] X. H. Liang, M. J. Zuo, and M. Pandey, "Analytically evaluating the influence of crack on the mesh stiffness of a planetary gear set," Mechanism and Machine Theory, vol. 76, pp. 20-38, 2014.

[10] A. Kapelevich and Y. Shekhtman, "Tooth fillet profile optimization for gears with symmetric and asymmetric teeth," in Proceedings of the American Gear Manufacturers Association Fall Technical Meeting 2008, pp. 73-83, USA, October 2008.

[11] X. Tian, M. J. Zuo, and K. R. Fyfe, "Analysis of the vibration response of a gearbox with gear tooth faults," in Proceedings of the 2004 ASME International Mechanical Engineering Congress and Exposition, pp. 785-793, Calif, USA, November 2004. 


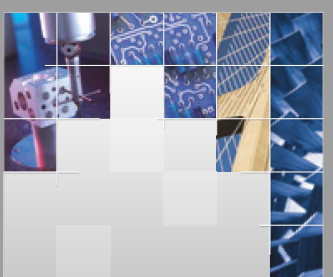

\section{Enfincering}
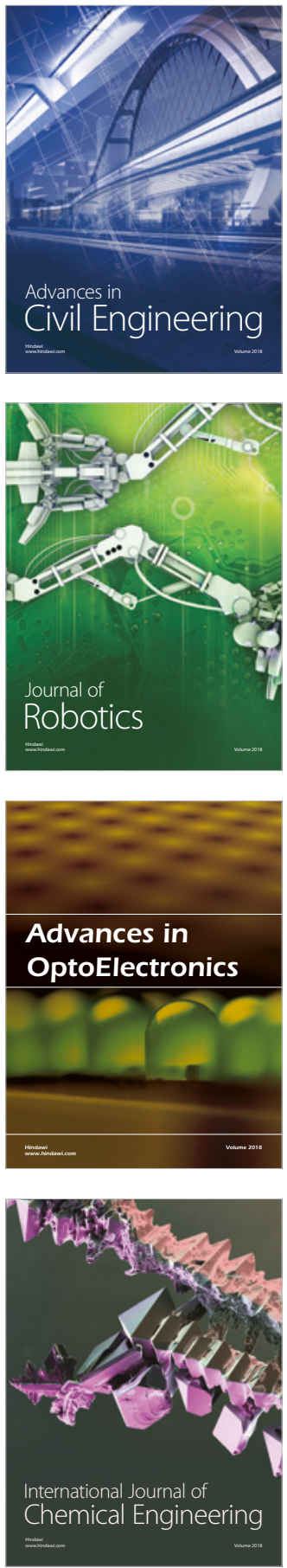

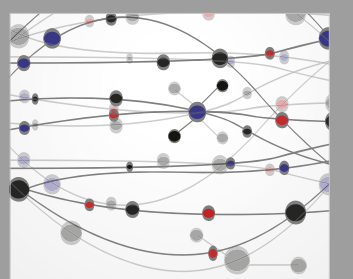

\section{Rotating \\ Machinery}

The Scientific World Journal

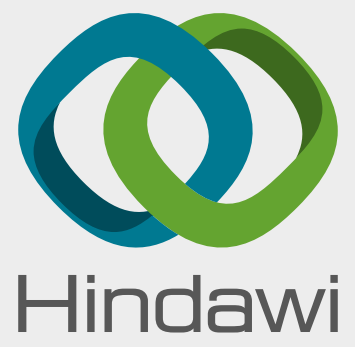

Submit your manuscripts at

www.hindawi.com
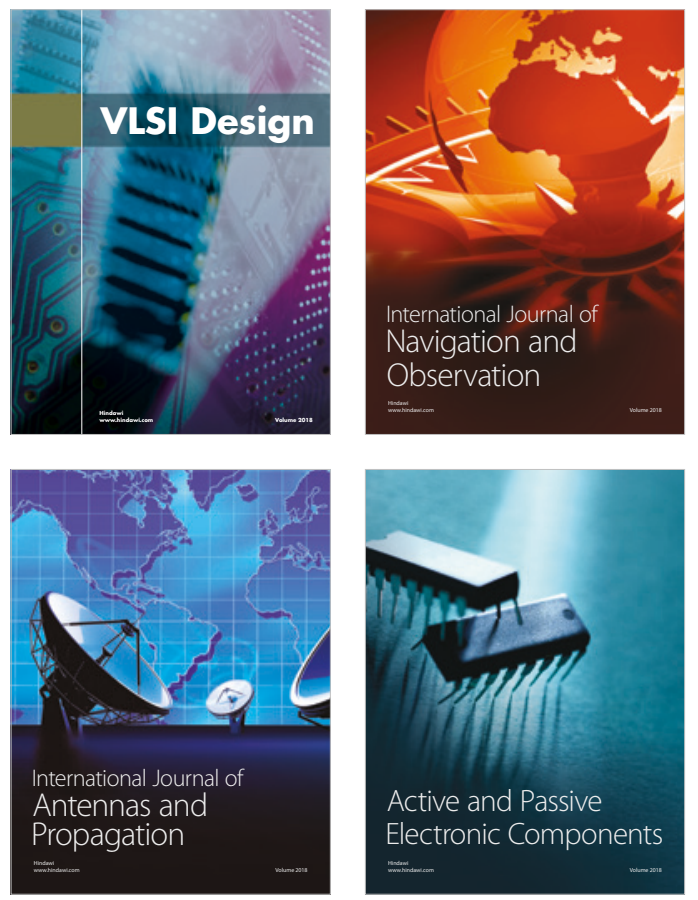
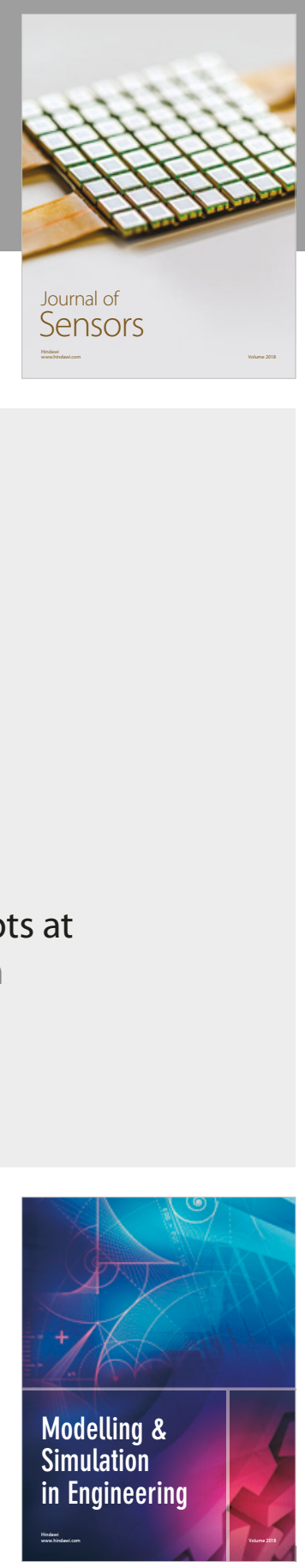

\section{Advances \\ Multimedia}
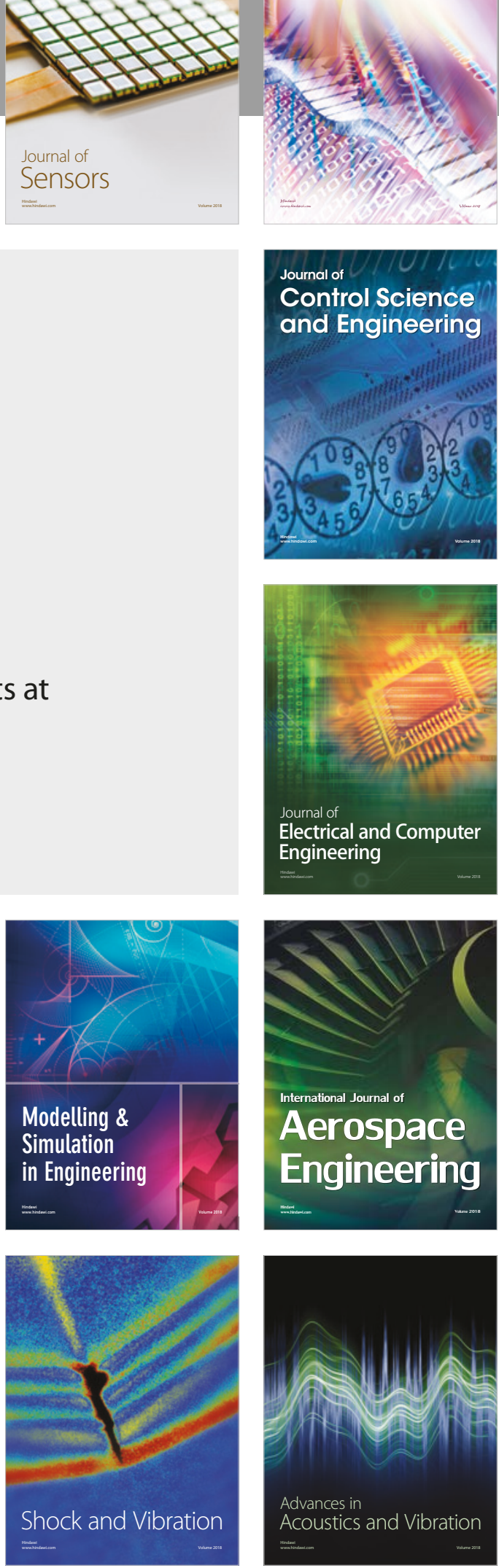